\title{
Performatividad en Judith Butler: Una introducción al concepto y sus fuentes*
}

\author{
Performativity in Judith Butler: An introduction to the concept and its \\ sources
}

\author{
Por: Núñez, Facundo Ariel ${ }^{*}$ \\ IIGHI/CONICET - UNNE. \\ E-mail: fan91091@gmail.com
}

Fecha de recepción: 15/03/2020

Fecha de aprobación: 30/04/2020

DOI: $10.30972 /$ ach.054317

\section{Resumen}

El primer período de producción intelectual de Judith Butler, que abarca desde 1990 hasta el 2004, se inscribe en el marco de la crítica cultural feminista y la teoría queer, desde donde la autora ha volcado sus esfuerzos en demostrar la inexistencia de una cierta esencialidad natural que pueda servir de fundamento al pensamiento cisgénero $y$ heteronormativo. Para desarrollar tal actividad Judith Butler se sirve del concepto de performatividad, llevando a cabo una caracterización inicialmente fragmentada del mismo, por tanto a tenido que responder y profundizar en sus desarrollos a partir de las críticas y malinterpretaciones que ha recido su obra.

Así pues, al no estar enmarcado dentro de una definición estricta este concepto ha ido adquiriendo diferentes particularidades a medida que la reflexión crítica de la filósofa estadounidense avanzaba; por este motivo es necesario, no solo reconstruir los desarrollos que Judith Butler realiza en relación a la noción de performatividad, sino también, analizar las fuentes a partir de las cuales se llevan a cabo las antes mencionadas profundizaciones a su teoría, para de ese modo lograr una comprensión más completa del concepto analizado.

\footnotetext{
* El presente artículo surge en el marco de mi trabajo como pasante del Instituto de Investigaciones Geohistóricas (IIGHI/CONICET), y miembro del proyecto de investigación "Procesos de subjetivación e institucionalización en problemáticas filosóficas contemporáneas" (P.I. 16-H002. Res. 970/16).

*Estudiantx de la Licenciatura en Filosofía de la Facultad de Humanidades (UNNE).
} 
Abril 2020.

ISSN 2344-9934

El presente trabajo se propone, por tanto, reconstruir los caracteres más significativos de lo que Judith Butler entiende por performatividad, analizando los distintos aportes teóricos que la autora desarrolla en los libros que se inscriben dentro de su primer período, y complementando los mismos con las diferentes fuentes filosóficas y psicoanalíticas que la pensadora estadounidense utiliza para nutrir su pensamiento, manteniéndonos siempre dentro de los límites intelectuales demarcados por la filósofa norteamericana.

Palabras clave: Judith Butler, performatividad, iteración, forclusión, genealogía.

\section{Abstract}

Judith Butler's first period of intellectual production, which ranges from 1990 to 2004, falls within the framework of feminist cultural criticism and queer theory, from where the author has turned her efforts - among other objectives and conceptual and political developments. - in demonstrating the absence of a certain natural essentiality that can serve as the basis for cisgender and heteronormative thinking. To develop such activity Judith Butler uses the concept of performativity, carrying out a fragmented characterization of it, therefore she had to respond and deepen her developments from the criticisms and misunderstandings that her work has received.

Thus, not being framed within a strict definition, this concept has acquired different peculiarities as the critical reflection of the American philosopher advanced, for this reason it is necessary, not only to reconstruct the developments that Judith Butler makes in relation to the notion of performativity, but also, analyze the sources from which these modifications are made in your thinking, to thereby achieve a deeper understanding of the concept analyzed.

The present work proposes, therefore, to reconstruct the most significant characters of what Judith Butler understands by performativity, analyzing the different theoretical contributions that the author makes in the books that are inscribed within her first period, and complementing them with the different philosophical and psychoanalytic that the American thinker uses to nourish her thinking, always keeping us within the intellectual limits demarcated by the author.

Keywords: Judith Butler, performativity, iteration, foreclosure, genealogy. 


\section{Cómo citar este artículo:}

APA: Núñez, F. A. (2020). Performatividad en Judith Butler: Una introducción al concepto y sus fuentes, Acheronta, 5, 57-78. Recuperado de: (agregar dirección web)

\section{Introducción}

El presente trabajo tiene por objetivo aportar herramientas para una reconstrucción de la noción de performatividad en el pensamiento de Judith Butler, abordando no solo las conceptualizaciones que la autora lleva a cabo, sino también aquellas fuentes de las cuales nutre su pensamiento. En relación con lo anterior, somos conscientes de que la presente es una empresa llevada a cabo por multiplicidad de autorxs, dentro de una variedad de formatos de trabajo y contextos, pero sinj embargo, no creemos que por ello el tema esté cerrado, más aun teniendo en cuenta la multiplicidad de interpretaciones y aproximaciones que se presentan a la hora de hablar de esta temática y las que con ella se relacionan ${ }^{1}$. Así pues, consideramos que las siguientes páginas permiten una introducción general a los aportes de una de las autoras más importantes y leídas del siglo XXI, intentando mantener una perspectiva objetiva acorde con los desarrollos de Judith Butler, evitando introducir elementos ajenos a su pensamiento.

A nivel metodológico, el presente trabajo surge de un cierto desglose de los desarrollos de Butler en sus obras, para su posterior reconstrucción. Vale la pena mencionar en este punto la dificultad que presentan las obras de la filósofa estadounidense, en las cuales es muy difícil encontrar una conceptualización precisa de los términos que utiliza, tal es el caso del concepto de performatividad, originalmente tomado de la filosofía de John Austin, al cual la autora va profundizando con el agregado de otrxs autorxs: Jacques Lacan, Jacques Derrida, Julia Kristeva, Michel Foucault, Luce Irigaray, entre otrxs. La lectura, fichado y esquematización, así como también el seguimiento y reposición de los aportes incluidos las las notas al pie dejadas por Butler en sus obras, fueron las técnicas que guiaron la presente indagación.

1 Sería difícil resumir en un solo punto todos los trabajos que se llevan a cabo sobre este temática, a manera de ejemplo mencionaremos los libros de Femenías (2003) y Canseco (2017), resaltando que pese a abordar una misma autora, lo hacen desde perspectivas distintas. En este sentido, nuestro trabajo pretende ser una introducción conceptual a obras más elaboradas y complejas. 
Abril 2020.

ISSN 2344-9934

Así pues, iniciaremos nuestro trabajo abordando el punto de partida, vinculándolo con la noción de genealogía entendida en un sentido foucaultiano - recordando que la metodología del autor francés se vincula indefectiblemente con los aportes de Friedrich Nietzsche -, intentando comprender la empresa que Judith Butler inició en 1990 con El género en disputa, y el modo en que la misma condiciona sus posteriores desarrollos teóricos. A partir de ese desarrollo daremos lugar al análisis de la noción de performatividad, intentando reconstruir la caracterización que Judith Butler lleva a cabo, mientras ponemos en relación esos aportes de la autora con las fuentes de las cuales se sirve su pensamiento, siguiendo sus indicaciones y notas para no introducir elementos ajenos a su teoría. De este modo finalmente incursionaremos brevemente en las posibilidades de subversión o escape a esta matriz, explicando así, no solo el funcionamiento de los mecanismos performativos de género, sino también algunas de las propuestas por la autora para superar los mismos, y para abrir la participación a las identidades forcluídas².

Vale aclarar que hemos decidido elaborar este escrito siguiendo el llamado "lenguaje inclusivo" ${ }^{3}$, con las dificultades que eso plantea tanto para la redacción como para la lectura; consideramos que dicha elección se fundamenta en la concepción del lenguaje presente en los trabajos analizados de Judith Butler.

\section{La genealogía del género}

Los desarrollos de Judith Butler inician como una crítica a ciertas corrientes al interior del feminismo: podríamos resumir la misma recuperando su propuesta, desde la cual plantea que la noción de género no debe ser presupuesta, es decir, que el punto de partida desde el cual el feminismo elabore su posición para oponerse a los desarrollos del androcentrismo, no debe partir de una cierta precomprensión de lo que implica la femineidad o el ser mujer, como si hubiese una suerte de esencialismo o naturalidad en dicha caracterización. Lo mismo puede

2 Como veremos posteriormente, Judith Butler utiliza los términos forcluído y abyecto para referirse a cierto tipo de identidades que exceden la matriz de inscripción cultural. Si bien consideramos que ambos conceptos parecen caer en un registro quizás extremo por la posición específica que determinan, su utilización es necesaria para mantenernos fieles a los desarrollos de Judith Butler.

3 Hemos decidido optar por la utilización de la X y el artículo "Ix" para evitar el uso del masculino inclusivo recomendado por la RAE. Ej.: A la hora de hablar de un elemento cualquiera de un conjunto específico utilizaremos "Ix niñx" en vez de "el niño". 
decirse de los demás géneros e identificaciones ${ }^{4}$, a partir de lo cual la autora desarrolla las conclusiones que se siguen de esta posición crítica (Butler, 2016); si no nos detenemos exhaustivamente en este punto es porque el mismo se vincula más con lo que hace al funcionamiento interno del feminismo como movimiento, punto sobre el cual nos consideramos poco capacitados como para desarrollarlo con el rigor teórico que merece ${ }^{5}$.

Ahora bien, el punto que si nos interesa es su rechazo a la noción de género como elemento con base natural, ya sea entendiendo al mismo como una cierta esencialidad, o como una traducción social de una marca de naturaleza - posición que caracteriza la perspectiva estructuralista derivada de los desarrollos de Levi-Strauss, entre otrxs -. En este sentido, lo que la autora lleva a cabo es una indagación genealógica acerca de los orígenes del género, en el prólogo de 1990 a El género en disputa, Judith Butler (2016) escribe "Considerar que las categorías fundacionales del sexo, el género y el deseo son efectos de una formación específica del poder requiere una forma de cuestionamiento crítico que Foucault, reformulando a Nietzsche, denomina 'genealogía'." (p.37).

Para analizar este primer elemento teórico abordaremos, por un lado, la primera de las cinco conferencias dictadas por Michel Foucault en Río de Janeiro en 1973, reunidas en el libro La verdad y las formas jurídicas, y por otro, el libro Nietzsche, la genealogía, la historia, cuyo original en francés fue publicado en 1971. Consignamos los años de ambas obras para resaltar su cercanía cronológica, entendiendo que la misma nos permite también vincularlas en un sentido más profundo, lo cual nos va a permitir lograr una comprensión más acabada de lo que Foucault entiende por genealogía, concepto y metodología que luego caracterizará su obra.

"Si el genealogista se toma la molestia de escuchar la historia [...] ¿Qué descubre? Que detrás de las cosas hay 'otra cosa bien distinta': no su secreto esencial y sin fecha, sino

\footnotetext{
$4 \quad$ En el prólogo de 1999 a El género en disputa, Judith Butler menciona que se sorprende al saber que dicha obra a sido considerada una de las bases de la teoría queer. La misma toma muchos elementos de la crítica a la noción de género, en particular en lo que hace a su naturalidad. Posteriormente, en Cuerpos que importan, Butler llegará al punto de afirmar que aun el sexo responde a una construcción y no a una raíz natural, lo cual posee una serie de complicaciones de tipo ontológicas que hemos decidido no abordar en el presente trabajo por cuestiones de extensión.

5 Para Butler (2017), el problema radica en que desde diferentes sectores del feminismo académico de los años 90 , se recurra a lo femenino como estructura conceptual a partir de la cual nuclear los desarrollos y reclamos. El problema radica en cómo se define ese concepto, qué cuestiones se dejan dentro y cuáles se dejan de lado, y más aun, cómo se comportaría dicho desarrollo desde la dualidad femenino/masculino, donde el segundo término siempre parece poseer una preeminencia sobre el primero.
} 
el secreto de que no tiene esencia, o de que su esencia fue construída pieza a pieza a partir de figuras extrañas a ella." (Foucault, 2004, p.18).

La anterior cita nos permite comprender el tipo de actividad que caracteriza a la genealogía, y por ende, su vinculación con el pensamiento de Judith Butler. Para profundizar más debemos pasar al análisis exhaustivo que Foucault realiza de los términos utilizados por Nietzsche a lo largo de su obra.

Al hablar del origen de algo, entendido esto en un sentido casi divino, Foucault (1995, 2004) establece que, dentro de la lengua alemana, debemos utilizar el término Ursprung. Ahora bien, en las dos fuentes antes mencionadas, el filósofo francés refiere que, a lo largo de su producción intelectual, Nietzsche nunca utiliza esa palabra en particular, sino que en su lugar utiliza otros tres términos, que si bien funcionan en cierto sentido como sinónimos, nos permiten, a partir de sus notas características, delimitar el tipo de actividades y saberes por los cuales se interesa la genealogía.

El primero de estos términos es Herkunft, el cual hace referencia a la procedencia, a la pertenencia a un grupo, y a menudo hace interferir a la raza o el tipo social del individuo analizado. Sin embargo, este análisis no busca encontrar los caracteres que pueden ayudar a asimilar a unxs con otrxs, sino descubrir la compleja red de marcas sutiles que se entrecruzan en Ixs sujetxs de análisis y que permite separar las marcas diferentes; la seña de la procedencia se encuentra en Ixs cuerpxs, y por tanto Ixs mismxs deben ser tenidxs en cuenta a la hora de hablar de una perspectiva genealógica.

El segundo concepto del que se sirve Foucault, recurriendo a los textos de Nietzsche, para explicar el objeto de la genealogía es el término Entstehung, el mismo hace referencia a la emergencia, al punto de surgimiento, a los principios y leyes singulares de una aparición, haciendo una salvedad: sería equivocado explicar la emergencia por el último término, más bien, se debe entender que este último término no es más que el episodio actual en una serie, y por lo tanto, nadie puede vanagloriarse de ser el artífice de esa emergencia, la misma excede a Ixs sujetxs que determina.

El tercer término que Nietzsche utiliza por oposición a Ursprung, y que es retomado por Michel Foucault, es Erfindung, este concepto se encuentra más desarrollado en la antes mencionada primer conferencia (Foucault, 1995), pero de todos modos mantiene una estrecha relación con lo anteriormente expuesto: Erfindung es la invención que, frente al carácter noble 
y elevado del origen, se nos presenta como algo bajo, mezquino, inconfesable y que plantea una ruptura, y en este sentido - y siguiendo la lectura foucaultiana de Nietzsche - las invenciones no serían más que el producto emergente de oscuras relaciones de poder, y la genealogía tendría como un tercer objetivo, que se suma a los anteriores sin excluirlos, sacar a la luz las mismas.

Ahora bien, vale recordar que lo que estamos analizando no es el modo en que Nietzsche comprendía la genealogía en sus desarrollos filosóficos, sino más bien la reapropiación foucaultiana de la misma. Dejando esa aclaración de lado, creemos que a la luz del desarrollo previo se puede comprender mejor, o al menos desde una perspectiva distinta, la empresa llevada a cabo por Judith Butler. Cuando ella analiza el género en un sentido genealógico ve marcas que atraviesan a lxs cuerpxs y les determinan un lugar de reconocimiento, estas a su vez, exceden a todx sujetx y establecen que no hay, ni puede haber, unx intérprete previx que determine la emergencia del género, a la vez que comprende que este último elemento desde una compleja matriz de relaciones, la cual se naturaliza permaneciendo así oculta de toda teorización.

El análisis genealógico se vincula además con la producción de la verdad, es decir, frente a la caracterización que hemos realizado previamente se opone otro discurso, uno para el cual las verdades poseen un origen, una Ursprung. Frente a esta perspectiva, Judith Butler, continuando en cierta medida la posición de Foucault, propone un análisis del género que permita comprender el caracter artificial del mismo, vinculando este desarrollo a la lucha en contra de un cierto discurso que establece una matriz normativa binaria, dentro de la cual se inscribe un arquetipo de varón y de mujer, y el modo válido de interrelación de los mismos. Foucault (1992) dirá "La verdad es, en suma, una verdad que solo puede desplegarse a partir de su posición de lucha o de la victoria que quiere obtener, de algún modo en el límite de la misma supervivencia del sujeto que habla." (p.61). Así pues, no hay una verdad objetiva y absoluta, lo que hay son discursos con pretención de verdad puestos al servicio de determinadas posiciones dentro de una matriz de relaciones.

Si no encontramos mayores dificultades a la hora de trasladar estos argumentos al pensamiento butleriano, quizás se deba a que la autora, como lo hemos dicho, continúa ciertas posiciones foucaultianas, entre ellas el desarrollo de discursos que desestabilicen las verdades absolutas, permitiendo la reaparición de aquellos sectores que permanecen en una situación de abyección debido, como veremos, a los mecanismos performativos del género: 
Abril 2020.

ISSN 2344-9934

"La cuestión de saber quién y qué se considera real y verdadero es aparentemente una cuestión de saber. Pero es también, como Michel Foucault aclara, una cuestión de saber. Tener o mostrar la 'verdad' y la 'realidad' es una prerrogativa enormemente poderosa dentro del mundo social, una manera mediante la cual el poder se disimula como ontología." (Butler, 2018b, p.48).

\section{Performatividad: de Austin a Derrida}

Judith Butler toma la noción de performatividad de los desarrollos teóricos de John Austin (Butler, 2016; Femenías, 2003), para dicho autor pueden llevarse a cabo tres clases de actos distintos con palabras: los locucionarios, ilocucionarios y perlocucionarios. Los primeros se refieren al mero hecho de hablar, el proferir palabras que llevamos a cabo cotidianamente; los actos ilocucionarios son aquellos que realizamos al decir algo, es decir, aquellos que implican un cierto accionar o compromiso a hacerlo por parte del emisor o del receptor, por ejemplo una promesa o una orden; por su parte, los actos perlocucionarios son aquellos que buscan generar una modificación en el comportamiento a las actitudes del oyente, pensemos por ejemplo en una argumentación o un debate (Austin, 2003); estos últimos dos tipos son los interesan a la autora estadounidense, pues determinan el modo en que las palabras pueden crear o determinar acciones y eventos. María Luisa Femenías, respecto al carácter perlocucionario de los actos de habla, afirma "Butler adopta y extiende esta última noción porque le importa la fuerza o el poder que estos actos tienen sobre otros individuos y sobre el mismo hablante, y sobre todo, su capacidad de producir cambios y transformaciones intencionales." (Femenías, 2003, p.114).

Así pues, si bien hemos adelantado que no podemos hablar de una formulación de un concepto claro y definitivo de performatividad en la obra de Judith Butler, sin embargo si encontramos caracterizaciones y delimitaciones del mismo, a partir de las cuales trataremos de llevar a cabo nuestra reconstrucción del concepto. Tomaremos como punto de partida una cita de la introducción a Cuerpos que importan, la cual establece que "la performatividad debe entenderse, no como un 'acto' singular y deliberado, sino, antes bien, como la práctica reiterativa y referencial mediante la cual el discurso produce los efectos que nombra (Butler, 2018a, p.18). 
Ahora bien, si entendiésemos la performatividad en el sentido estricto de un acto ilocucionario/perlocucionario terminaríamos creyendo que unx es dueñx de sus actos, o más bien, que hay una cierta persona que tiene la capacidad de crear cosas, o determinar disposiciones, a partir del simple hecho de enunciarlas y comprometerse con ese discurso; ahora bien, esto iría en contra de lo que hemos visto al hablar de la genealogía como estudio de la emergencia, allí mencionamos que nadie puede atribuirse la posición central, no hay unx sujetx que se encuentre al inicio y que de marcha a la cadena de acontecimientos, a la manera de un motor inmóvil. En el último apartado del primer tomo de La historia de la sexualidad, Michel Foucault (2008) establece que el poder crea Ixs cuerpxs - entendidos estos como conjuntos de fuerzas - que luego regulará, es decir, Ixs sujetxs emergen a partir de una matriz de discursos - posteriormente desarrollaremos mejor este punto - y son determinadxs por esta. Solo gracias a esta matriz pueden llegar a ser reconocidxs como identidades válidas.

“El 'sexo' no es pues sencillamente algo que uno tiene o una descripción estática de lo que uno es: será una de las normas mediante las cuales ese 'uno' puede llegar a ser viable, esa norma que califica un cuerpo para toda la vida dentro de la esfera de la inteligibilidad cultural." (Butler, 2018a, p.19).

Lo dicho alcanza para comprender que, a pesar de que hablemos del caracter construído de las nociones de sexo y género, no debemos entender que de esto se siga que sea un proceso voluntario o personal. Ahora bien, continuando con la caracterización es importante comprender que la performatividad quizás ni siquiera deba ser considerada como un acto, o no al menos siempre que este término implique un accionar aislado.

Para Judith Butler la performatividad opera como una iteración, es decir, como una repetición en el tiempo de fórmulas discursivas estilizadas, lo cual le otorga a estas un cierto poder sobre la realidad. Este es un concepto tomado de la filosofía de Jacques Derrida, quién en una conferencia pronunciada en 1971 reflexiona, precisamente, acerca de la noción de performatividad tal y como la presenta Austin. Para Derrida la capacidad de hacer de las palabras viene dada por una cadena de reiteraciones, es decir, por una citación autoreferencial constante de determinadas fórmulas, lo cual permite solidificarlas en el tiempo, otorgándoles así capacidades ilocucionarias y perlocucionarias.

"Un enunciado performativo ¿podría ser un éxito si su formulación no repitiera un enunciado 'codificado' o iterable, en otras palabras, si la fórmula que pronuncia para abrir una sesión, botar un barco o un matrimonio no fuera identificable como 
Abril 2020.

ISSN 2344-9934

conforme a un modelo iterable, si por tanto no fuera identificable de alguna manera como 'cita'?"' (Derrida, 1971, pp. 21-22).

Pero a la vez que la iteración confiere a las normas de sexo y género un carácter prescriptivo - la fórmula "es una niña" acompaña a la persona desde su nacimiento, prefigurando un determinado camino que deberá seguir para ser inscripta dentro del registro de lo válido - también es necesario que las mismas se naturalicen en Ixs cuerpxs, entendiendo por este término duraciones temporales sostenidas culturalmente. La inscripción en los cuerpos también se lleva a cabo por intermediación del lenguaje, o quizás sea más exacto afirmar que es la cultura la que posee un rol central, entiendo por esta el conjunto de preceptos socialmente aceptados que configuran el modo de percibir la realidad y el mundo que nos rodea; nuestro acceso a la realidad se da por intermedio del discurso, o más bien, de un cierto discurso considerado como válido y que determina posiciones específicas de reconocimiento.

\section{Habitus y performatividad: proximidades y distancias}

Los desarrollos previos que hemos llevado a cabo vinculan, hasta cierto punto, la noción de performatividad de Judith Butler con la de habitus de Pierre Boudieu, concepto del cual el sociólogo francés se sirve para expresar los mecanismos que permiten la incorporación de la estructura social a través de la posición que se ocupa en la misma, a la vez que da forma a las prácticas y representaciones que se ponen en juego en el contexto específico de un espacio cultural delimitado y aceptado (Bourdieu, 1998).

Recurriendo a una conocida y ampliamente citada fórmula, el habitus funciona como una estructura que es, a la vez, estructurante y estructurada (Bourdieu, 1998). Estructurada por tanto es la sociedad la que ha ido definiendo los roles y las normas asignadas a cada uno a partir de la reproducción de un modelo cultural, y de ciertos valores comúnmente aceptados; y es estructurante pues define el tipo de experiencias que se espera lleve a cabo cada unx de Ixs sujetxs que forman parte de ese cuerpo social. El habitus marca la interiorización, la naturalización en un cuerpo, de las normas que le son impuestas por el contexto en el cual se inscribe, en nuestro caso particular, las normas de sexo y género, pero lo mismo puede aplicarse a los diferentes preceptos sociales, ya sean explícitos o tácitos. 
La noción de performatividad y la de habitus se vinculan hasta cierto punto delimitando negativamente con este movimiento una zona de diferenciación entre ambas teorías -, y si resaltamos que esta vinculación es solo parcial, es debido a la mediación crítica que Judith Butler realiza en relación al concepto del autor francés. Para este último, el rol social determinaría las capacidades del sujeto, así como también su lenguaje - entendiendo a este como la inscripción del individuo en un marco socio-cultural específico -, esta estructura implicaría que las posiciones superiores del nivel social tienen una preeminencia a la hora de interpretar el mundo, por tanto poseen más capital simbólico y cultural, y tienden a conservarlo, mientras que las posiciones inferiores parecen estar empujadas a una dependencia de aquellas, y a un cierto fracaso - inevitable si se tiene en cuenta lo anterior - a la hora de intentar reelaborar los términos que hacen posible su reconocimiento. Frente a esto Butler dirá que:

“Los performativos no sólo reflejan condiciones sociales previas, producen además un conjunto de efectos sociales, y aunque éstos no siempre son efecto del discurso 'oficial', sin embargo influyen en el poder social no sólo regulando los cuerpos, sino también formándolos. Es más, las acciones del discurso performativo exceden y perturban los propios contextos autorizados de los cuales han surgido." (Butler, 2004 ,p.255).

Así pues, si igualásemos la noción de performatividad a la de habitus no habría manera de poner en marcha algún mecanismo de subversión, a partir del cual las realidades postergadas podrían intentar alcanzar un mayor estatuto de reconocimiento desde su posición particular, pues - desde la perspectiva bourdiana tal y como Judith Butler la interpreta - el lenguaje y las capacidades de Ixs sujetxs estarían completamente determinadas por la matriz social. Conforme avancemos en el presente trabajo veremos que el mecanismo mismo a partir del cual opera la performatividad, ofrece ciertas herramientas, desde las cuales sería posible poner al mismo en su contra, o desmontarlo por completo.

Consideramos que este apartado, si bien breve, no solo permite empezar a distanciar los desarrollos de Butler de algunas posiciones que - a priori - parecen cercanas, sino que también, a partir de los desarrollos previos, podemos previsualizar los desarrollos que llevaremos a cabo posteriormente. Conservemos, por tanto, la idea de que el mecanismo de performatividad no es una estructura labrada en la piedra, el mismo puede ser desmontado y puesto a trabajar en su contra. Pero para poder comprender mejor estas estrategias, o al 
Abril 2020.

ISSN 2344-9934

menos su posibilidad de emergencia, es preciso desarrollar el modo en que Butler interpreta la inscripción de la cultura y el lenguaje - el dominio de los simbólico - en el sujeto.

\section{La esfera de lo simbólico}

La fuente principal - a nuestro entender - a partir de la cual comprender el proceso mediante el cual las normas de sexo y género son asumidas por las personas, implica recurrir a los desarrollos de de Jacques Lacan. Ahora bien, consideramos preciso aclarar las dificultades que presenta la lectura de este autor, y el hecho de que nuestro hilo conductor para abordar el mismo ha sido la lectura de El género en disputa; se sigue de ello que quizás caigamos en errores a la hora de enunciar los alcances y desarrollos de los conceptos lacanianos. Para Lacan, el yo solo puede surgir una vez que se supera el dilema edípico, a este punto Judith Butler añadirá que junto con la prohibición del incesto para que el niño supere esta etapa de su desarrollo también deberá asumir la prohibición de la homosexualidad, por tanto cuando el niño realiza el duelo por la madre, entiéndase el primer objeto de deseo imposible, debe evitar una identificación con la misma que desplace la prefiguración del deseo, la interiorización de la madre debe asegurar la heterosexualidad, lo cual prefigura en cierta medida el rechazo a determinadas posiciones consideradas imposibles: la homosexualidad, la transexualidad, el travestismo. Como podremos ver más adelante, este agregado de Butler tiene consecuencias fundamentales a la hora de pensar en nuestra relación con esas imposibilidades.

Retomando los desarrollos lacanianos, mientras Ixs niñxs se mantienen en el estadío previo a la aparición del yo, se encuentran en un contexto definido por una ambivalencia semántica absoluta, no hay una referencialidad directa a partir de la cual establecer cadenas de sentidos, de lo cual se sigue que el lenguaje, entendido como herramienta de comunicación que establece relaciones semánticas semi-estrictas, aun no aparece. De esto se sigue que el lenguaje solo puede asumirse en el momento en que se supera el conflicto edípico, se realiza el duelo por la madre, se la interioriza - idealmente siguiendo el modelo que hemos mencionado previamente -, y se da lugar al surgimiento del yo. Este lenguaje así conquistado configura la esfera de lo simbólico, Ix sujetx ingresa en esta esfera una vez que asume su nombre, pasando a formar parte del lenguaje que ahora se presenta como una red de significantes entrelazados (Dor, 1995; Masotta, 1988). 
Si el hombre supera el dilema edípico es por el miedo a la castración como castigo, mientras que la mujer lo hace por el miedo a no ser castrada; del hombre Lacan dirá que tiene el falo, es decir, que es capaz de crear significados y aparentemente no está determinado por ninguna posición (siempre que la misma no implique una vuelta al incesto o la homosexualidad), mientras intenta encarnar la Ley del Padre, entiéndase, una serie de determinaciones normativas que, a la vez que regulan la actividad del sujeto, ayudan a ordenar su psiquis y su lugar en el plano de lo simbólico. La mujer, por su parte, en tanto personificación de la castración, es el falo, afirma Lacan, y requiere del hombre, quien tiene el falo, para que la determine: "Por tanto, 'ser' el falo es siempre 'ser para' un sujeto masculino que desea volver a corroborar e incrementar su identidad a través del reconocimiento de ese 'ser para'." (Butler, 2016, p.118), pero debido a que la mujer es el falo, esta, a su vez, encarna efectivamente la Ley del Padre; vemos de esta manera una dinámica similar a la conocida dialéctica del amo y el esclavo de Hegel, vinculación resaltada por la autora ${ }^{6}$.

Ahora bien, Judith Butler insiste, recurriendo al análisis de los textos de Lacan, en que estas identificaciones nunca son absolutas, es decir, ni el hombre puede jamás representar completamente la ley paterna, y por eso tiene el falo pero no lo es, mientras que la mujer se identifica con una ley que nunca puede evidenciar, pues no se refiere directamente a ella (Butler, 2016). De esto se sigue que, por un lado, las normas y el lenguaje pueden ser entendidos como elementos coextensivos, por tanto la Ley del Padre se asume a partir de la inscripción en lo simbólico; y por el otro, que las identificaciones nunca son absolutas, siempre existe un cierto grado de imposibilidad. Si sumamos esto último a nuestra comprensión previa de la performatividad del género como práctica iterativa vemos que, en cada momento de la apelación a la cita, es posible una cierta ruptura, una cierta discuntinuidad, y que por tanto los modelos nunca son asumidos de forma absoluta, siempre poseen un carácter fantasmático. Comprender este elemento es clave para el posterior análisis de los modelos de desestabilización de la matriz cultural performativa, pero a su vez, implica que siempre habrá un cierto grado de violencia, utilizada como mecanismo de reafirmación de los límites entre lo permitido y lo abyecto (Butler, 2017; 2018b).

6 A lo largo de la obra de Judith Butler - desde un momento tan temprano como su tesis encontramos múltiples conexiones entre sus desarrollos y los de G. W. F. Hegel. Un análisis minucioso de esta interrelación se encuentra en la obra Eroticidades precarias. La ontología corporal de Judith Butler (Canseco, 2017). 


\section{Lo abyecto y lo forcluído}

Lo antes expuesto nos permite comprender, en mayor profundidad, cómo se lleva a cabo el proceso de naturalización de las normas de sexo y género, mediante su inscripción en el lenguaje. En este punto podríamos coincidir con Michel Foucault cuando menciona en Vigilar y castigar, que lo que se disciplina es el alma, entiéndase una cierta interioridad de Ixs sujetxs, lugar de articulación de los mecanismos de poder, que finalmente repercuten en el accionar y en las disposiciones del cuerpo (Foucault, 2014).

Ahora bien, como también hemos mencionado previamente, esta determinación no implica que estemos absolutamente obligadxs a repetir dicha matriz normativa eternamente, o que no se puedan dar modificaciones al interior de la misma. El proceso de iteración, tal y como lo hemos explicado, abre la oportunidad para lo imprevisto, para lo diferente. De este modo, no deben buscarse fuentes de oposición al exterior del proceso performativo, más bien debe entenderse que este genera el espacio de ruptura (Butler, 2016), pero lo encubre por medio de la abyección.

Judith Butler toma el concepto de abyección de la obra de Julia Kristeva, quien inicia su libro Poderes de la perversión de la siguiente manera:

"Hay en la abyección una de esas violentas y oscuras rebeliones del ser contra aquello que lo amenaza y que le parece venir de un afuera o un adentro exorbitante, arrojado al lado de lo posible y de lo tolerable, lo pensable". (Kristeva, 2006, p. 7).

Debemos entender por abyecto aquello que excede las capacidades de representación de Ixs sujetxs, algo que se presenta hasta cierto punto como un imposible - en este punto es buen recordar lo que hemos dicho previamente acera de la prohibición de la homosexualidad por la superación del dilema edípico y la configuración de posiciones imposibles -. Esta categoría se articula como una oposición al yo, por lo tanto, la abyección se caracteriza por la exclusión, por determinar de manera negativa las posibilidades permitidas de realización y acción ${ }^{7}$. Sin embargo, esto no implica que haya una separación absoluta entre los dos términos

7 Vale la pena mencionar en este punto una cierta relación entre estos desarrollos y los de Giorgio Agamben $(2004,2010)$, en particular en lo que hace a su interpretación del estado de excepción y su conceptualización de la nuda vida. Desde dicho margen de interconexión, las identidades abyectas se presentan como vidas desnudas, sometidas sin más a la violencia del poder, mientras habitan una zona de exclusión, no necesariamente determinada en un sentido geográfico, que permite delimitar las reglas específicas de reconocimiento al interior del espacio prefigurado por su expulsión. 
de esta relación, como la cita anterior lo establece, lo abyecto es una constante amenaza, algo que, pese a encontrarse afuera, puede reingresar.

Para profundizar esta conceptualización Judith Butler se sirve del concepto lacaniano de forclusión, el mismo puede ser entendido como la expulsión del registro de lo representable de un cierto significante que genera conflictos en el yo. Dicho elemento no es reprimido, pues eso implicaría que pase a formar parte del inconsciente de Ix sujetx, es decir, aun estaría al interior de Ix mismx, y por tanto la amenaza permanecería. El proceso de forclusión implica una expulsión al plano de lo real, entiéndase, lo absolutamente irrepresentable, exterior al sujeto. Si eso que ha sido forcluído reingresase al plano de lo simbólico implicaría la disolución del yo, la neurosis (Laplanche y Pontalis, 2013).

Estas dos nociones, se ponen en relación con la noción de performatividad a la hora de pensar en aquellxs cuerpxs que no se adecúan a las normas. Es decir, "Esta matriz excluyente mediante la cual se forman los sujetos requiere pues la producción simultánea de una esfera de seres abyectos, de aquellos que no son 'sujetos', pero que forman el exterior constitutivo del campo de los sujetos." (Butler, 2018a, p.19). Las identidades que no se adecuan a las exigencias de la matriz simbólica son expulsadas, forcluídas, y pasan a formar el límite de lo posible. La condición de abyectas implica que estas realidades no sean comprensibles para Ixs sujetxs válidxs, pues en grado sumo son impensables. ${ }^{8}$

Ahora bien, este recorrido teórico - que en nuestra realidad cotidiana hay un sector que es expulsado como condición de posibilidad de lo válido - se nutre, como hemos dicho, de los desarrollos de Julia Kristeva, pero a la vez es profundizado a partir de los aportes de Luce Irigaray y Monique Wittig. La primera de dichas autoras aborda los textos filosóficos preguntándose acerca de su constitución, es decir, qué se tuvo que dejar de lado para que la filosofía pueda constituirse como tal, desde su perspectiva de análisis del Fedón de Platón, por ejemplo, lo que permanece abyecto es la mujer, es decir, el discurso filosófico se elabora a partir de la exclusión de la mujer, e Irigaray emprende la relectura de las fuentes buscando eso que aparece como una elipsis, eso que no está presente pero que deja una marca de omisión (Butler, 2018a). Para Monique Wittig, tanto el sexo como el género son categorías con intereses políticos, las cuales se naturalizan y establecen un cierto grado de sexualidad

8 Desde este punto se puede comprender, por nombrar solo un caso, el hecho de que en Corrientes la ley de cupo laboral trans se mantenga en un proceso de revisión constante, mientras transexuales, transgéneros y travestis no pueden acceder a fuentes de trabajo formal, lo cual repercute directamente en su calidad y esperanza de vida (Agencia Presentes, 2018). 
Abril 2020.

reproductiva obligatoria, se sigue de estos desarrollos que aquellas actividades sexuales que no se vinculen con una finalidad reproductiva no son reconocidos, motivo por el cual concluye que las lesbianas no pueden ser consideradas mujeres; vemos en este punto otra utilización de la figura de la abyección, esta vez vinculada a la homosexualidad. Así como el trabajo para Irigaray consiste en realizar una lectura que muestre las marcas de una ausencia, la empresa de Wittig está marcada por el llamado a derrumbar la categoría de sexo y la obligación heterosexual en la cual se origina (Butler, 2016).

“El sujeto está obligado a repetir las normas que lo han producido, pero esa repetición crea un ámbito de riesgo porque, si no consigue restituir las normas 'correctamente', se verá sujeto a sanciones posteriores y sentirá amenazadas las condiciones imperantes de su existencia." (Butler, 2001, p.40).

El acatamiento de las normas viene acompañado, constantemente a lo largo del proceso iterativo, por la amenaza de abyección, es decir, de la negación del reconocimiento. Ahora bien, hemos dicho que las identidades nunca se asumen completamente, que son más bien fantasmáticas, se sigue de ello que en las actividades cotidianas Ixs sujetxs deben reafirmar los límites de lo válido, y con este movimiento reasegurar su lugar al interior de la esfera de lo reconocible. En este sentido se llevan a cabo una multiplicidad de prácticas con el objetivo de confirmarle - a los dos elementos de esta dualidad: lo abyecto y lo válido - su lugar, puesto que, como hemos mencionado previamente, Ixs cuerpxs forcluídxs son los que determinan las fronteras de lo permitido. Entre estas actividades nos gustaría abordar el insulto como un mecanismo tanto de reafirmación de los límites, como así también de subversión, pero sin dejar de mencionar que, en nombre de lo natural se han perdido innumerables vidas, y que un discurso que se basa en la exclusión nunca es solo eso.

\section{Violencia y subversión en el lenguaje}

Creemos que, con lo desarrollado hasta aquí, es posible tener una visión global del proceso performativo, tal y como es desarrollado por Judith Butler y en relación con las fuentes de las cuales se nutre su pensamiento. Sin embargo, si solo nos quedásemos con eso, parecería que la performatividad es un proceso del cual no podemos salir, y a Ixs cuerpxs abyectxs no les quedaría más que asumir una posición de eterno fracaso. 
Hemos dicho previamente, al analizar la conceptualización lacaniana de la construcción del yo, que las identidades, aun aquellas que se inscriben dentro de los marcos de lo permitido y lo esperado, nunca se llegan a configurar absolutamente, es decir, siempre hay un cierto grado de imposibilidad en el arquetipo fantasmático. Esta misma imposibilidad es la que brinda la posibilidad para la subversión.

Para explicar mejor este punto, Judith Butler, recurre a la noción de interpelación desarrollada por Louis Althusser. Para dicho pensador, el llamado de atención por parte de la autoridad es lo que constituye al sujeto socialmente: Ix policía como representante de la ley, interpela a unx sujetx con la fórmula "oiga, usted", en ese momento, dichx sujetx se inscribe en la la matriz legal que Ix policía representa, es decir, el llamado de atención por parte de la autoridad policial funciona como un proceso iterativo - por tanto su efectividad proviene más de la repitición de una figura estilizada y consolidada - que crea lo legal y lo ilegal partiendo de la interpelación misma (Butler, 2018a). Ahora bien, siguiendo las consecuencias de este desarrollo dentro del pensamiento butleriano se abren dos posibilidades de desarticulación de la matriz performativa, por un lado la cita parodiada de la ley, y por el otro, la reapropiación de los términos de la exclusión como espacio de enunciación.

La primera de estas dos posibilidades es ampliamente trabajada por Judith Butler en EI género en disputa, la perspectiva de entender al género como travestido - noción que generó muchos malentendidos que la autora debió rectificar en Cuerpos que importan -. Entendamos bien este punto, cuando se vincula el travestismo con el género no se quiere afirmar que haya una suerte de jerarquía de identidades, no se da una preeminencia a lxs travestis como espacio de lucha, no se exige que adoptemos esas prácticas. Lo que Butler intenta explicar es que, en su actuar, Ixs travestis o Ixs drags, exhiben el caracter construído de las nociones de género, es decir, muestran un proceso de identificación con un cierto ideal que nunca puede ser realizado: una persona drag queen, por ejemplo, exhibirá en su aspecto una teatralización absoluta de ciertas características que, comúnmente, se asocian al género femenino, pero llevadas a un grado extremo, mostrando el carácter arbitrario de la determinación de roles y posiciones.

“Como consecuencia de una performatividad sutil y políticamente impuesta, el género es un 'actor', por así decirlo, que está abierto a divisiones, a la parodia y crítica de uno mismo o una misma y a las exhibiciones hiperbólicas de 'lo natural' que, en su misma 
exageración, muestran su situación profundamente fantasmática." (Butler, 2006, p.285).

Así pues, cuando la norma obliga a Ixs sujetxs a responder y a articularse dentro de lo permitido, estxs pueden responder recurriendo a identificaciones paródicas, las cuales en lugar de repetir y validar la matriz performativa, muestran el carácter artificial de la misma. Un gesto de ruptura que se vale de los elementos mismos de la estructura opresiva para exhibir los puntos débiles de la construcción de las identidades válidas.

Pero esta no es la única posibilidad, como lo hemos adelantado. La interpelación funciona como un nombramiento, una designación que establece el lugar de una determinada persona en el lenguaje - solo a través de este movimiento es posible que esa persona ingrese en el campo legal, en este caso, como unx infractorx -. Ahora bien, al abordar los aportes de Lacan hemos visto que la inscripción en el marco de los simbólico se da por el nombre, por el llamado, momento a partir del cual se puede asumir un lugar activo dentro del lenguaje. Judith Butler (2016) afirma: "El poder del lenguaje para trabajar sobre los cuerpos es al mismo tiempo la causa de la opresión sexual y la vía que se abre más allá de esa opresión" (p.233).

Anteriormente hablamos de las prácticas que se llevan a cabo, desde el interior de la matriz performativa, con el objetivo de afianzar sus límites y afirmar la posición que le corresponde a las identidades abyectas. El insulto es uno de estos mecanismos, es la inscripción dentro del lenguaje de lo abyecto, con el objetivo de reconducir las prácticas que se desvían de lo normado. Así pues, cuando un hombre interpela a otro diciéndole "puto" intenta mostrarle que, o bien las actividades que está llevando a cabo no son deseables, o bien, que su lugar es por fuera del ámbito social reconocible en el cual se encuentra. Pero a la vez, ese otro que es interpelado puede responder, pues el insulto, al ser entendido como nombramiento, brinda la oportunidad para la inscripción en el plano de lo simbólico, para reapropiarse de un lenguaje que le es ajeno, y para consolidar una posición de oposición al interior del mismo. Judith Butler (2016) afirma "El 'yo' que se opondría a su construcción siempre parte de algún modo de esa construcción para articular su oposición" (p.181). Y María Femenías (2003) explica:

"El lenguaje ofensivo ofrece la posibilidad de inaugurar agencia en un sujeto que utiliza el lenguaje como contraofensiva. [...] Como no se puede aniquilar la fuerza del otro, se la toma como punto arquimídeo. En consecuencia, solo se puede socavar la hegemonía significativa de un término, resignificándolo." (p.133). 
Se pueden brindar múltiples ejemplos acerca de esta mecánima de subversión, Judith Butler menciona el desarrollo del término queer, el cual pasa de ser un agravio a un punto de articulación y respuesta de determinados sectores forcluídos ${ }^{9}$. De modo similar, en Argentina y en el NEA, podemos ver como en las marchas de la comunidad LGBT+, o en las de los colectivos feministas, se rearticulan palabras que otrora fueron un agravio como un espacio de lucha, un lugar de identificación común para el grupo a partir del cual enunciar sus reclamos. El insulto, de acuerdo a este último punto, es una posibilidad abierta a Ixs cuerpxs forcluídxs para ser escuchadxs, reingresar en la esfera de lo autorizado y exigir una vida digna, igual a la de todo ser humano.

No obstante lo anterior, es importante tener en cuenta que esta alternativa, en tanto opción para la subversión, presenta peligros inherentes, al igual que toda estrategia que se ponga en juego en una lucha de intereses, más aun si se hace desde el sector más desfavorecido. Afirmar taxativamente que el insulto es la opción por excelencia para la articulación de la lucha implica un cierto grado de apología de la violencia, y se basa en la exposición de las identidades abyectas a la misma; no es nuestra intención afirmar ninguna de estas dos posiciones. Si hemos incluído este punto en nuestro trabajo fue para mostrar que el mecanismo por el cual opera la performatividad no es un proceso a prueba de fallas, existe el espacio para la irrupción de lo nuevo, el cual debe llevarse a cabo desde la militancia y los espacios de visibilización.

\section{Conclusión}

Consideramos que lo expuesto hasta aquí brinda una herramienta de introducción, un camino de análisis de las nociones de performatividad y de las conceptualizaciones vinculadas en los desarrollos de Judith Butler. A partir de este punto, como hemos podido mencionar, se pueden seguir diferentes caminos que profundicen en las diferentes aristas que hemos

$9 \quad$ En un breve artículo publicado en la revista Parole de Queer, Beatriz Preciado recupera la historia del término. "Queer", en sus orígenes en la lengua inglesa, se refiere a lo extraño, lo raro, lo anómalo; con estas determinaciones fue aplicado, en primera medida, al colectivo de varones homosexuales, remarcando el carácter desviado de los mismos. Ahora bien, a partir de la irrupción del VIH como epidemia, durante los años 80 , el término fue tomado como un espacio de unidad y contención, frente a un contexto que condenaba sus prácticas y respondía de manera agresiva a las mismas. Posteriormente, el término fue ampliado, dejando atrás los límites de la comunidad gay y refiriéndose a todas aquellas identidades que se posicionaban por fuera de los límites de lo binario en un sentido amplio dando lugar a nuevas identidades de género y a espacios de lucha en contra de la limitación misma. (Preciado, 2009). 
exhibido. No obstante lo cual, las páginas que preceden una sólida base para comprender tanto los posteriores desarrollos de Ixs autorxs que vinculan sus trabajos con Butler, así como también los nuevos aportes teóricos de la autora.

El presente trabajo se inscribe en una tradición que, si bien ha sido abordada en múltiples oportunidades desde diferentes sectores, lejos está de ser una situación acabada, la discriminación y la violencia sobre la base de una estructura de sexo-género demanda una respuesta, requiere desarrollos que problematicen las estructuras represivas, y acompañen las luchas y los reclamos. Siguiendo los desarrollos de Foucault y Butler, la actividad de Ixs investigadorxs e intelectuales no debe desvincularse de la actividad política. En este sentido, y retomando la posición del intelectual foucaultiano - aquel que no se ubica por fuera de las luchas, ni tampoco intenta marchar al frente iluminando el camino, sino que se inscribe en el conflicto - las páginas que preceden son un intento de sumar argumentos en contra de una serie de posiciones que, bajo la idea de una cierta naturalidad o esencialidad, imponen una lógica discursiva marcada por la discriminación y el odio hacia aquellas identidades que pretenden escapar a los patrones de reconocimiento aceptados.

Consideramos que hablar no es solo proferir palabras, nuestros enunciados tienen un peso iterativo específico, tienen el peso de fórmulas que permiten moldear el modo en que se percibe la realidad, y los elementos que están autorizados a formar parte de la misma. Con esto no queremos restringirnos a las marcas sexo-genéricas, sino pensar en todos los modos de inscripción de un cuerpo, en toda esa estructura hay lugares considerados válidos y posiciones imposibles, y el cuerpo social reacciona a esas posiciones imposibles - pensemos, a manera de ejemplo breve, el rechazo que generan las manifestaciones en el cuerpo social, Ix sujetx políticamente activx es otro imposible -. Comprender el modo en que los procesos performativos operan y se estilizan en el tiempo permite poner en marcha estrategias que, si bien no los eliminen, al menos permitan un espacio de apertura para aquello que comúnmente permanece fuera de nuestra percepción del mundo.

Finalmente, creemos necesario aclarar que el presente trabajo se elaboró sobre el concepto de performatividad, es decir, se tomó de los libros de Judith Butler aquello que pudiese ayudar a comprender mejor dicho concepto. Esta perspectiva deja de lado las críticas que la autora realiza a otrxs pensadorxs, pues en muchos casos la misma no agrega elementos para comprender el punto que nos interesaba, sino que más bien muestra, en qué medida la visión de Butler aporta otros elementos de análisis - por ejemplo, la crítica que hace a la 
noción de lo semiótico de Julia Kristeva, en El género en disputa -, o bien, muestra las incoherencias internas en el pensamiento de unx autorx determinado - sobre este punto gira la crítica que realiza a Michel Foucault -. Otro elemento que se dejó de lado, fue la vinculación que Judith Butler lleva a cabo entre su teoría, y aportes provenientes del cine o la literatura, tomemos por caso su reflexión acerca de la ficción de Willa Cather, o su análisis de Paris is burning, documental dirigido por Jennie Levingston; en ambos casos, y en muchos otros, consideramos que el recurso a estas fuentes sirve como un modo de ejemplificación, o como una aplicación de la performatividad como categoría de análisis, aunque, conceptualmente, no nos brinda elementos nuevos para profundizar los desarrollos que nos interesan.

\section{Bibliografía}

- Agamben, G. (2004) Homo sacer, II, I. Estado de excepción. Buenos Aires, Argentina: Adriana Hidalgo editora

- Agamben, G. (2010) Homo sacer I. El poder soberano y la nuda vida. Valencia, España: Pre-textos

- Austin, J. (2003) Como hacer cosas con palabras. Buenos Aires, Argentina: Paidós

- Bourdieu, P. (1998) La distinción. Criterio y bases sociales del gusto. Madrid, España: Taurus Ediciones

- Butler, J. (2001) Mecanismos psíquicos del poder. Teorías sobre la sujeción. Valencia, España: Ediciones Cátedra

- Butler, J. (2004) Lenguaje, poder e identidad. Madrid, España: Editorial Síntesis, S.A.

- Butler, J. (2016) El género en disputa. Buenos Aires, Argentia: Paidós

- Butler, J. (2018a) Cuerpos que importan. Buenos Aires, Argentina: Paidós

- Butler, J. (2018b) Deshacer el género. Buenos Aires, Argentina: Paidós

- Derrida, J. (1971) Firma, acontecimiento, contexto. Recuperado de https://www.ddooss.org/articulos/textos/derrida firma.pdf

- Canseco, A. (2017) Eroticidades precarias. La ontología corporal de Judith Butler. Córdoba, Argentina: Ed. Asentamiento Fernseh

- Dor, J. (1995) Introducción a la lectura de Lacan. Madrid, España: Gedisa.

- Femenías, M. (2003) Judith Butler: una introducción a su lectura. Buenos Aires, Argentina: Catálogos S.R.L.

- Foucault, M. (1992) Genealogía del racismo. Madrid, España: Ediciones de La Piqueta 
Abril 2020.

ISSN 2344-9934

- Foucault, M. (1995) La verdad y las formas jurídicas. Barcelona, España: Gedisa

- Foucault, M. (2004) Nietzsche, la genealogía, la historia. Valencia, España: Pre-textos

- Foucault, M. (2008) Historia de la sexualidad 1. La voluntad de saber. Buenos Aires, Argentina: Siglo veintiuno editores

- Foucault, M. (2014) Vigilar y castigar. Nacimiento de la prisión. Buenos Aires, Argentina: Siglo Veintiuno Editores

- Kristeva, J. (2006) Poderes de la perversión. Buenos Aires, Argentina: Siglo Veintiuno Editores

- Laplanche J. y Pontalis J. (2013) Diccionario de psicoanálisis. Buenos Aires, Argentina: Paidós

- Masotta, O. (1988) Introducción a la lectura de Jacques Lacan. Buenos Aires, Argentina: Corregidor

- Preciado, B. (2009) Historia de una palabra: Queer. En: Parole de Queer. Num. 1 (Abril - Junio), pp. 14-17. 